\title{
Research on the Training Strategies of Infants' Reading Ability
}

\author{
Lina Zhang \\ Teachers' College Shenyang University \\ Shenyang, China
}

\author{
Sizhuo Chen \\ Taiyi Experimental Kindergarten Huanggu District \\ Shenyang, China
}

\begin{abstract}
The experimental results show that the reading ability of infants is the driving force for the development of their abilities in all aspects. The aim of this paper is to understand infants' reading level well and improve their reading ability. By using documentary method, the paper analyzes the situation of infants' reading ability accurately, finds out existing problems, explores its causes and develops a set of strategies to improve their reading ability and then to promote their comprehensive development.
\end{abstract}

Keywords-Infants; Reading ability: Training strategies; Preschool education

\section{INTRODUCTION}

\section{A. Infant}

Infant refers to preschool children aged 0-6.

\section{B. Reading ability}

Reading ability refers to the ability to master and understand the overall meaning of the articles. The reading ability mentioned in this paper refers to the ability of preschool children aged 0-6 to apperceive children's literature.

\section{Training strategies}

Strategy refers to the stratagem. The training strategies mentioned in this paper refer to the strategies developed to cultivate and improve the reading ability of preschool children and to promote the development of their reading ability.

\section{STATUS QUO OF DEVELOPMENT LEVEL OF INFANTS READING ABILITY}

\section{A. Status quo of reading ability level of infants aged 0-3}

1) Stronger early learning ability and reading potential

Modern psychological research proves that infants aged 0 3 have stronger early learning ability and reading potential, their vocabulary and reading ability develop rapidly, and the learning speed can even be twice that of adults [1]. In addition, they have the ability of active exploration and have a relatively obvious early learning trend.

\section{2) Stronger ability of word recognition}

Related studies have shown that it is easier for infants to master the relationship between fonts and entities than to master the relationship between speech and entities [2]. Therefore, infants aged 0-3 have a stronger ability of word recognition before they begin to learn to speak. Some common Chinese characters or pictures will attract the attention of infants in the process of reading

\section{3) Stronger reading interest}

0-3 years old is a sensitive period for infants to receive external stimuli and a critical period for the formation of certain abilities. In this period, infants will have a strong interest in reading picture books and story books, and will accumulate some early reading experience in the process to prepare for future reading. This period is also an important way for adults to lead infants into the reading world and to inspire infants to learn independently.

\section{B. Status quo of reading ability level of infants aged 3-6}

1) Overall analysis of reading ability of infants aged 3-6

At this age stage, the infant reading begins to slowly shift from the picture reading stage to the word reading stage. At this time, the improvement of infants' reading ability is not only reflected in the symbolic function of beginning to understand the words, but also in the recognition of some common simple Chinese characters in life. For example, small, big, medium, one, upper, and cattle. At the same time, parents will find that when children start to try to read books, their attention will often focus on the Chinese characters they have known in the process of parent-child reading.

2) Concrete analysis of reading ability of infants aged 3-6

The infants aged about 3 not only show a strong interest in reading, but also master the basic reading methods; At the same time, their interest in the words has been greatly improved, and some simple words can be recognized and read under the inspiration and guidance of adults.

The reading comprehension ability of infants aged 4 is significantly improved, and the ability to predict the development of the story line is significantly enhanced; They can initially master the simple Chinese character reading rules, will try to use some unique ways to practice some of the basic strokes of Chinese characters. 
The reading ability of Chinese characters of infants aged 56 has been further developed. They will try to learn the correct writing posture and lay the foundation for the learning of Chinese character writing through interesting graphic exercises.

\section{PROBLEMS AND CAUSES OF READING ABILITY OF INFANTS}

\section{A. Problems and causes of reading ability of infants aged 0-3}

1) Attach importance to the mastery of knowledge and ignore the cultivation of interests

Most teachers and parents focus on the mastery of literacy and knowledge by infants rather than the development of reading interests and reading habits according to a survey of early reading of infants in some kindergartens and families. This practice is mainly influenced by traditional educational ideas, and has a negative impact on the development of infants' reading ability.

2) There are fewer optional books, and kindergartens or parents have improper choices.

From the perspective of the current situation of the Chinese book market, there are very few books that are really suitable for infants aged $0-3$, with more or less quality problems. In addition, some kindergartens lack the responsibility they deserve, and many parents lack the related knowledge of infants' reading education, so there are improper problems in selecting books for infants.

3) Parents lack proper guidance for early reading activities

Since many parents go out to work, most infants aged 0-3 are left in the care of their elders. The thoughts of the elders are more traditional, so they pay more attention to the basic necessities of life of infants, and ignore the early reading of infants. Related studies have shown that only a small number of parents carry out the reading activities with their children, but single method makes the reading effect poor.

\section{B. Problems and causes of reading ability of infants aged 3-6}

1) The independent reading in the kindergarten isn't valued

According to the collected document literature, 9 of the 17 early reading activities carried out in a kindergarten didn't include the independent reading components [3]. This is enough to show that infants don't fully play their autonomy when reading in kindergarten. The reason is that on the one hand, there is a limited number of reading books provided by kindergartens for infants, and on the other hand, the kindergarten teachers pay less attention to the independent reading activities of infants.

2) In the kindergarten reading carriers, the role of readers is ignored

According to the document literature, teachers only use some larger books or play PPT courseware [4] to carry out the collective early reading activities carried out in most kindergartens. This way is very easy to cause the infants to be inattentive due to relatively far distance from the reading carrier. The reason is that on the one hand, there is a small number of reading books due to limited funds in kindergartens, and on the other hand, the importance of readers as a reading carrier isn't well known to kindergartens.

\section{3) Early reading activities in kindergartens are unsystematically}

According to the document literature, early reading activities account for a small proportion of the daily teaching activities in kindergartens [4]. In addition, teachers have greater randomness in choosing readers for infants, and rarely consider the internal connection between the readers. The main reason is that kindergartens lack scientific understanding of the law of development of infants' reading ability and the significance of carrying out reading activities.

4) The family reading presents a "primary school" tendency

According to the document literature, many parents have begun to realize the importance of early reading for the development of children in all aspects, and have purchased a large number of picture books for their children. At the same time, they also take picture books as a tool to increase the amount of recognized characters of their children and gradually enter the error area of "primary school". It is mainly because the idea of "Don't let the children lose at the starting line" affects most parents.

\section{5) The family reading environment isn't suitable}

According to the document literature, most parents choose to carry out the parent-child reading with their children in bed instead of in the study. There are also some parents who have no time to carry out the reading activities with their children. This phenomenon shows that there is still large deficiency for the material conditions of the parent-child reading environment not only in the choice of space, but also in the time arrangement. It is mainly because parents lack the theoretical knowledge of infants' reading education.

\section{6) Single interactive mode of family reading}

Most parents generally use language-based instructional methods such as reading feeling and discussion and communication methods when conducting the parent-child reading with their children and rarely adopt the methods which can mobilize multiple senses of infants and strengthen parentchild interaction, such as role playing, story creation, etc. It is mainly because parents lack professional reading guidance.

\section{STRATEGIES FOR DEVELOPING THE READING ABILITY OF INFANTS}

\section{A. Strategies for developing reading ability of infants aged 0 -} 3

1) Create a good reading atmosphere and cultivate reading interest

First of all, parents should set a good example for infants and create a good reading atmosphere. Secondly, kindergartens should provide professional teachers, a positive atmosphere and a dedicated reading area for infants, and a variety of books for infants with different hobbies. Only in this 
way can infants naturally develop interest in reading in the process of growth.

2) Choose appropriate reading works according to the development characteristics of infants

Infants aged 0-3 often realize the knowledge and understanding of things by senses stimulation, so parents and kindergartens must choose a picture book with clear printing, rich colors and vivid patterns when choosing infants' reading works. At the same time, they should choose books with higher language repetition frequency, which not only can promote the development of infants' language ability, but also help infants to accumulate rich knowledge and vocabulary.

3) Pay attention to early reading activities and effectively guide the reading process

Parents should pay attention to early reading of infants. At the same time, their guidance for infants' reading should be the focus of early reading. Teachers and parents should encourage infants to observe and think more, and can also extend the reading contents through games, so that the reading ability of infants can be effectively improved.

\section{B. Strategies for developing reading ability of infants aged 3-} 6

1) Strengthen the guidance of independent reading activities

The key to early reading education is to develop the independent reading ability of infants. Infants will have a close contact with readers, ask questions while reading, and predict the ending of the story in the independent reading activities. So teachers should give full play to the guiding role, observe the reading and learning needs of infants in time, and provide targeted guidance for the needs of infants to improve their reading ability.

\section{2) Pay attention to the provision of teaching readers}

The number of readers provided by the kindergartens for infants has a great impact on the effect of early reading activities of infants. First of all, kindergartens should encourage parents to purchase appointed readers and to allow their children to bring them to kindergarten for sharing. Secondly, the number of children participating in the collective early reading activities can be determined according to the total number of readers, so that the infants can complete the early reading tasks in turn. Finally, the "reader relay" method can be adopted and a book is read multiple times, which not only can effectively save costs, but also can conform to the law of development of infants' reading ability.

\section{3) Promote systematic reading}

Early reading is a long systematic project. First of all, teachers should classify their readers, which is more conducive to infants' deep impression of a certain type of works. Secondly, early reading activities should have a fixed time in kindergartens, and long-term persistence is required. Thirdly, teachers should recommend some readers suitable for infants to read to parents, and encourage parents to carry out the parent-child reading activities with children, so that they can interact with collective reading activities.
4) Improve awareness of early reading values and avoid "primary school"

Parents can learn about the correlation theory of infants' reading education and understand the importance of early reading through the educational lectures held by kindergartens or consultations and other activities. Blindly taking reading education as a way of literacy by children only reduces the interest of infants in reading. In fact, early reading is not only conducive to the development of infants' intelligence, accumulation of knowledge and experience, but also is of positive significance to the infants' emotional development, habit formation and ability development.

5) Create a good parent-child reading environment and create a suitable psychological atmosphere

First of all, parents should create a comfortable and childish reading environment for infants at the preparation stage of parent-child reading. For example, set up a study room or a relatively open reading corner for children. Secondly, create a warm psychological reading atmosphere. For example, creating a reading atmosphere in the whole family and set an example of reading for children and each family member has good reading habits.

\section{6) Adopt an interactive reading strategy}

The first is language interaction. Parents interact with infants in reading contents through asking infants and give timely and correct guidance, so that the infants can fully express their thoughts in the process of reading picture books [5]. The second is emotional interaction. When the parentchild reading is conducted, children can snuggle in the arms of parents, enjoying the gentle words of the parents. At the same time, parents' guide the infants to connect the stories they hear with their own lives to enrich the emotional experience of the infants. The third is extended interaction. After the common reading is finished, parents can encourage their children to read the favorite picture books repeatedly, and guide them to retell the story line or to perform the plot by using the body movement.

\section{CONCLUSIONS}

The paper studies the training strategies of infants' reading ability in different angles and from all directions. The research conclusions are as follows: Create a good reading atmosphere and cultivate reading interest; Pay attention to early reading activities and effectively guide the reading process; Choose appropriate reading works according to the development characteristics of infants; Strengthen the guidance of independent reading activities; Pay attention to the provision of teaching readers; Promote systematic reading; Improve awareness of early reading values and avoid "primary school"; Create a good parent-child reading environment; Adopt an interactive reading strategy. 


\section{REFERENCES}

[1] Li WANG. Status quo and guiding strategies of family parent-child reading of infants aged 0-3 [D]. Master Thesis of Hebei University, 2014.

[2] Chan ZHANG. Status quo, problems and research countermeasures of parent-child picture book reading in early childhood [D]. Master Thesis of Shandong Normal University, 2015.

[3] Weixian SI How to effectively improve the early reading ability of infants [J]. Yangtze River Delta (Education), 2012.

[4] Qian XU. Status quo and problems of early reading activities of infants aged 0-3 - Taking Qiqihar institution for early education as an example [J]. Time Education, 2014 (02): 34-35.

[5] Yafang WU. Beautiful picture book, beautiful world-Discussion on the questioning strategies in picture book instruction [J]. New Curriculum (Volume I), 2016. 